\title{
Temporal and spatial expression of terpene synthase genes associated with agarwood formation in Aquilaria malaccensis Lam
}

\author{
Anor Basah Azzarina ${ }^{1}$, Rozi Mohamed ${ }^{1 *}$, Shiou Yih Lee ${ }^{1}$ and Mohd Nazre $^{2}$
}

\begin{abstract}
Background: The diseased wood, agarwood, from the tropical tree taxa Aquilaria, is famed for its unique fragrance and medicinal values, mainly due to its richness in secondary metabolites such as the sesquiterpenes. The presence of sesquiterpenes in high numbers and amounts correlates with agarwood of high quality.

Methods: To understand the synthesis of this important compound, we cloned two candidate genes in the terpenoid synthesis pathway from Aquilaria malaccensis Lam., a major agarwood tree species. The genes encoding sesquiterpene synthase (AmSesTPS1) and $\delta$-guaiene synthase (AmGuaiS1) were successfully cloned from callus RNA, using specific primers derived from transcriptomic data, in a reverse transcription PCR reaction.

Results: The full-length complementary DNA (CDNA) sequence of AmSesTPS1 was 1632 bp encoding for 544 amino acids, and AmGuaiS1 was 1644 bp encoding for 547 amino acids. Sequence alignment analysis showed that AmSesTPS1 shared between 99 to $100 \%$ identity with sesquiterpene synthase from Aquilaria sinensis (Lour.) Spreng. while AmGuaiS1 shared between 95 to $99 \%$ identity with $\delta$-guaiene synthases from Aquilaria crassna Pierre ex Lecomte and $A$. sinensis. The genes were functionally characterised in a time course wounding experiment using 3-year-old living trees. Two types of wood samples were collected: (1) from wounded area (S1) and (2) from $5 \mathrm{~cm}$ below the wounded area (S2). AmSesTPS1 was highly expressed after $6 \mathrm{~h}$ post wounding for both S1 and S2, at a level three- to six-fold higher than that of the unwounded control $(0 \mathrm{~h})$, while AmGuais 1 was induced after just $2 \mathrm{~h}$ of wounding (18- and 5.5-fold at S1 and S2, respectively), after which the expression of both genes was lowered. The average normalised expression of both genes at S1 and S2 indicates the genes were also upregulated in the distal area from the wounding site.
\end{abstract}

Conclusions: It can be deduced that wounding triggers these two genes in the sesquiterpene synthesis pathway, which ultimately leads to agarwood formation.

Keywords: Callus, Systemic reaction, Thymelaeaceae, Terpenoids, Wounding

\section{Background}

Aquilaria malaccensis Lam. is the first agarwoodproducing tree listed in the Appendix II of Convention on International Trade in Endangered Species of Wild Fauna and Flora in 1994 (CITES 1994). This tropical tree is of high economic interest because the agarwood it produces is being traded internationally. Agarwood, eaglewood, gaharu, aloeswood-these are just a few of

\footnotetext{
* Correspondence: rozimohd@upm.edu.my

${ }^{1}$ Forest Biotech Laboratory, Department of Forest Management, Faculty of Forestry, Universiti Putra Malaysia, 43400 UPM Serdang, Selangor, Malaysia Full list of author information is available at the end of the article
}

the names for the resinous, fragrant and highly valuable non-wood product produced by $A$. malaccensis and other species of the Indo-Malesian tree genus Aquilaria. Its production in the wood stem of Aquilaria species has been associated to the tree's defence system against abiotic and biotic factors. Abiotic factors, in particular the act of wounding, have been shown to be the main triggers of agarwood formation (Nobuchi and Mohd Hamami 2008) and this is naturally followed by infection from biotic agents such as fungi for trees in wild habitats (Mohamed et al. 2010; Mohamed et al. 2014b). 
In order to survive in the environment, plants have adapted a number of strategies and one of them is the production of secondary metabolites (Zhao et al. 2005). The major active compounds in agarwood are phenylethyl chromones and sesquiterpenes, which are known to have analgesic and sedative effects (Okugawa et al. 2000; Ueda et al. 2006). Agarwood extracts are rich with numerous types of sesquiterpenes such as guaiene, eudesmane, agarospiral and jinkoh-eremol (Yagura et al. 2003; Naef 2011). Guaienes are a series of closely related natural chemical compounds that have been isolated from a variety of plant sources. $\alpha$-Guaiene is the most common and was first isolated from guaiac wood oil from Bulnesia sarmienti Lorentz ex Griseb. (Bates and Slagel 1962). The guaienes are used in the fragrance and flavouring industries to impart earthy, spicy aromas and tastes. In Aquilaria, guaiene synthesis has been shown to follow the general terpene synthesis pathway established in higher plants, i.e. the cytosolic mevalonic acid (MVA) pathway (Xu et al. 2003). From the building precursor isoprenoid, subsequent enzymatic reactions take place, converting the precursor into several intermediates. At the end of the downstream process, highly specialised enzymes categorised as terpene synthases (TPSs) transform the intermediates into various structural types of terpenoids. Several important terpenoids in modern medicines are also synthesised via similar pathway such as the antimalarial agent artemisin in Artemisia annua L. and the Indian ginseng withanolides in Withania somnifera (L.) Dunal (Rasool and Mohamed 2015).

To better understand the mechanism by which active compounds in agarwood are synthesised, we studied the structure and function of two terpene synthases in Aquilaria malaccensis, the guaiene (AmGuaiTPSI) and sesquiterpene synthase (AmSesTPS1). Their functions in stress response were profiled in wood tissues collected at different intervals after mechanical wounding using qRT-PCR experiments. We report the first isolation of TPS gene from A. malaccensis using a reverse transcription approach.

\section{Methods}

\section{Plant materials}

Plantlets were grown from seeds that were sterilised and introduced into $1 / 2$ MS (Murashige and Skoog 1962) medium according to Daud et al. (2012). After 3 weeks, germinated shoots were cut and transferred into MS medium supplemented with $1.3 \mu \mathrm{M}$ 6-benzylaminopurin (BAP) (He et al. 2005). Plants were sub-cultured every 4 weeks into fresh medium until their height reached about $5 \mathrm{~cm}$. Plantlets were grown under a long-day condition with $16 \mathrm{~h}$ of light and $8 \mathrm{~h}$ of darkness at $25^{\circ} \mathrm{C}$. For the wounding experiment, 4-year-old $A$. malaccensis saplings were purchased from the Lentang Seed Centre,
Forestry Department Peninsular Malaysia, and kept under shade in the nursery at the Faculty of Forestry, Universiti Putra Malaysia (UPM), Serdang, Malaysia. Saplings were grown under natural environmental conditions in polybags and were watered daily.

\section{Wounding treatment}

Saplings were mechanically wounded using a drill machine equipped with a 3-mm-diameter drill bit. The stem was drilled into the xylem to a depth of 1 to $2 \mathrm{~cm}$. Wounding proceeded in a straight line along the stem, from $5 \mathrm{~cm}$ above the ground until the shoot, with $5 \mathrm{~cm}$ spacing between wounds. Three saplings were harvested at each time point and were designated as tree 1 (T1), tree 2 (T2) and tree 3 (T3) (biological replicates). Thus, a total of 24 trees were wounded at the same time and sampled at different time points after wounding: 2, 4, 6, $8,12,18,24$ and $48 \mathrm{~h}$ along with unwounded trees as a control representing $0 \mathrm{~h}$. The whole tree was harvested in each case, and two types of samples were pooled together from each tree to represent (1) wounded area (S1) and (2) $5 \mathrm{~cm}$ below S1 (S2) (Fig. 1). These discs were chopped into small pieces, mixed and a portion retrieved for RNA extraction. Samples were kept in ziplock bags at $-80{ }^{\circ} \mathrm{C}$ for RNA isolation.

\section{Total RNA extraction}

For gene cloning, total RNA was extracted from $0.5 \mathrm{~g}$ stem tissue collected from in vitro plantlets. For qRTPCR, $1 \mathrm{~g}$ wood tissue from the respective samples was used. The RNeasy Plant Mini Kit (Qiagen, Germany) was used in RNA extraction with a slight modification (Siah et al. 2012). DNase treatment was carried out using the DNA-free ${ }^{\mathrm{Tm}}$ Kit (Ambion, USA), according to the manufacturer's instructions. The concentration of RNA in samples was quantified using a nanophotometer (Implen, Germany). For RLM-RACE, callus tissues were used as starting materials (Jayaraman and Mohamed 2015), while in gene expression, $1 \mathrm{~g}$ of woody stem was used in RNA extraction.

\section{Synthesis of the first cDNA strand}

The first-strand of complementary DNA (cDNA) was synthesised using The SuperScript ${ }^{\mathrm{TM}}$ First-Strand Synthesis System for RT-PCR (Invitrogen, Brazil). The $10 \mu \mathrm{L}$ of reaction mixture consisted of $1 \mu \mathrm{g}$ of DNase-free RNA, $1 \mu \mathrm{L}$ of $50 \mathrm{ng} / \mu \mathrm{L}$ random hexamers and $8 \mu \mathrm{L}$ of DEPCtreated water. The mixture was incubated at $65{ }^{\circ} \mathrm{C}$ for $5 \mathrm{~min}$ and immediately placed on ice for at least $1 \mathrm{~min}$. The cDNA synthesis mix was prepared by adding $2 \mu \mathrm{L}$ of $10 \times$ RT buffer, $4 \mu \mathrm{L}$ of $25 \mathrm{mM} \mathrm{MgCl}_{2}, 2 \mu \mathrm{L}$ of $0.1 \mathrm{M} \mathrm{DTT}, 1 \mu \mathrm{L}$ of RNase Out $(40 \mathrm{U} / \mu \mathrm{L})$ and $1 \mu \mathrm{L}$ of SuperScript ${ }^{\mathrm{TM}}$ III RT $(200 \mathrm{U} / \mu \mathrm{L})$. Approximately, $10 \mu \mathrm{L}$ of $\mathrm{cDNA}$ synthesis mix was added to 


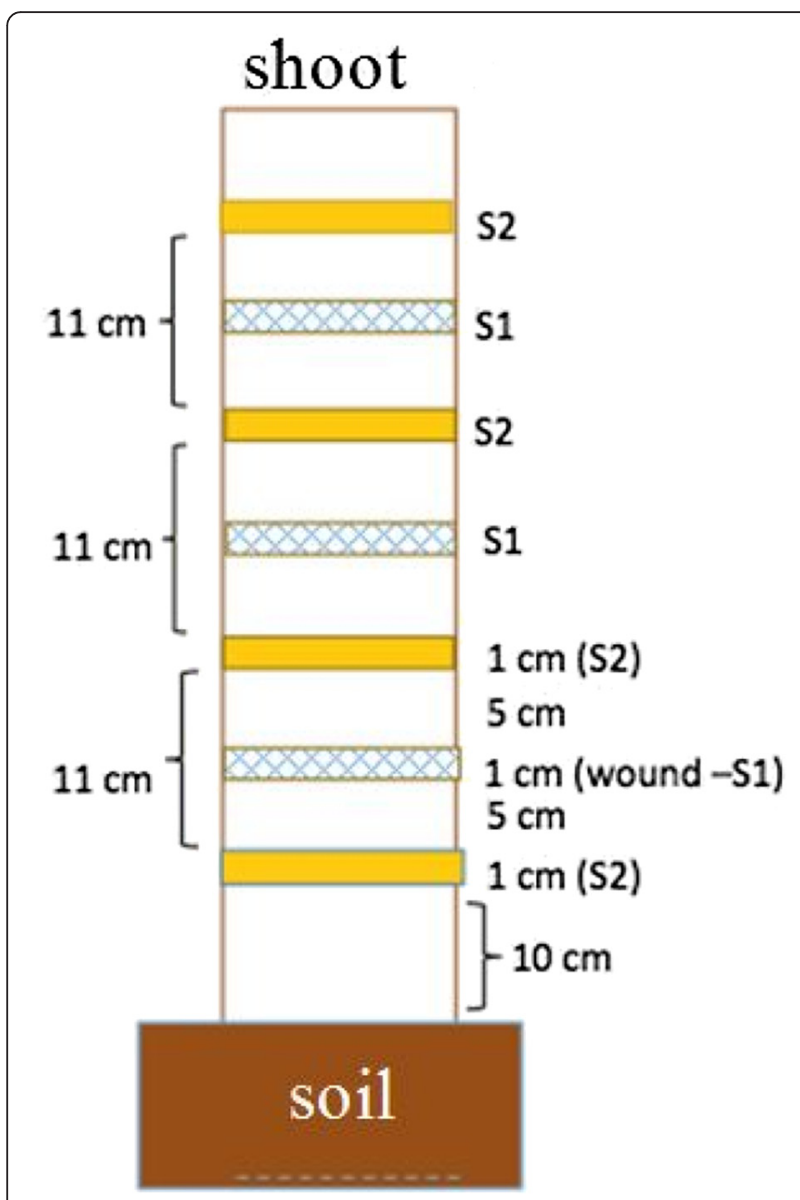

Fig. 1 A schematic drawing showing wounds and sample locations. The tree sapling was drilled into the xylem along the stem, starting $5 \mathrm{~cm}$ above the ground until the shoot in intervals of $5 \mathrm{~cm}$. After the designated time point, the whole tree was felled and two types of samples were taken: (1) wounded area (S1) and (2) $5 \mathrm{~cm}$ below S1 (S2)

each RNA/primer mixture, gently mixed, briefly centrifuged and incubated at $50{ }^{\circ} \mathrm{C}$ for $50 \mathrm{~min}$. The reaction was terminated in the water bath at $85{ }^{\circ} \mathrm{C}$ for $5 \mathrm{~min}$, chilled on ice and briefly centrifuged to collect the reaction. RNase $(1 \mu \mathrm{L})$ was added to each tube and was incubated for $20 \mathrm{~min}$ at $37{ }^{\circ} \mathrm{C}$. The cDNA was stored at $-20{ }^{\circ} \mathrm{C}$ for further usage.

\section{Partial-length cDNA cloning}

For gene cloning, specific primers were used to amplify two candidate genes encoding for sesquiterpene synthase and $\delta$-guaiene synthase, directly from the cDNA of an A. malaccensis stem. The primers were designed based on the transcriptome sequences of the candidate genes (Siah et al. 2016). Polymerase chain reaction (PCR) amplification was performed in the MyCycler Thermal Cycler (Biorad, USA). This process was carried out in a total volume of $25 \mu \mathrm{L}$ containing
$2.5 \mu \mathrm{L}$ of $10 \times$ PCR Buffer, $0.5 \mu \mathrm{L}$ of $10 \mathrm{mM}$ dNTP mix, $0.75 \mu \mathrm{L}$ of $50 \mathrm{mM} \mathrm{MgCl}, 2 \mu \mathrm{L}$ of forward and reverse primers at $10 \mu \mathrm{M}$ each, $2 \mu \mathrm{L}$ of cDNA template, $0.125 \mu \mathrm{L}$ of Taq Polymerase (Invitrogen, Brazil) and $15.125 \mu \mathrm{L}$ of autoclaved distilled water. The cycle parameters were an initial denaturation step at $94{ }^{\circ} \mathrm{C}$ for $5 \mathrm{~min}$, followed by 40 cycles of $94{ }^{\circ} \mathrm{C}$ for $30 \mathrm{~s}$, $60{ }^{\circ} \mathrm{C}$ for $30 \mathrm{~s}$ and $72{ }^{\circ} \mathrm{C}$ for $1 \mathrm{~min}$. The final extension at $72{ }^{\circ} \mathrm{C}$ for $10 \mathrm{~min}$. The PCR product was analysed in $1 \%$ agarose gel and the expected size was excised and purified using the QIAquick Gel Extraction Kit (Qiagen, Germany).

\section{Isolation of recombinant plasmid}

PCR products were cloned into the $\mathrm{pGEM}^{\circ}-\mathrm{T}$ Easy Vector (Promega, USA) following the manufacturer's protocol. Single bacterial colonies, positively identified as containing the respective plasmids from white/blue screening, were picked using sterile pipette tips, cultured in $5 \mathrm{~mL}$ Luria Bertani (LB) broth (Difco ${ }^{\mathrm{Tm}}$, USA) containing $5 \mu \mathrm{L}$ of $100 \mu \mathrm{g} / \mathrm{mL}$ ampicillin (Biobasic, Canada). Cultures were incubated at $37{ }^{\circ} \mathrm{C}$ and $150 \mathrm{rpm}$ overnight. Plasmid DNA purification was carried out using the QIAprep Spin Miniprep Kit (Qiagen, Germany). DNA from putative plasmids was sent for sequencing at a commercial company. Sequences were compared to known sequences at the GenBank (National Centre Biotechnology Information, NCBI) using BLASTX.

\section{Full-length cDNA cloning}

Total RNA $(10 \mu \mathrm{g})$ isolated from callus tissues was used in 5' RACE and 3' RACE using the First Choice RLMRACE (Ambion, USA) following the manufacturer's instructions. The Beacon Designer 7 (Biosoft, USA) was used to design gene-specific primers based on the sequences of the amplified partial fragments of the respective genes (Table 1). PCR was carried out in $50 \mu \mathrm{L}$ of mixture containing $1 \mu \mathrm{L}$ of RT reaction/outer PCR, $5 \mu \mathrm{L}$ of $10 \times$ PCR Buffer, $4 \mu \mathrm{L}$ of $2.5 \mathrm{mM}$ dNTP mix, $0.25 \mu \mathrm{L}$ of $5 \mathrm{U} / \mu \mathrm{L}$ Super Taq-Plus, $2 \mu \mathrm{L}$ of $10 \mu \mathrm{M}$ of each primer (5' RACE gene-specific outer primer and 5' RACE Outer Primer). Amplification was performed using a thermal cycler (BioRad, USA) according to the thermal cycling condition: initial denaturation at $94{ }^{\circ} \mathrm{C}$ (3 min) followed by 40 cycles of denaturation at $94{ }^{\circ} \mathrm{C}$ (30 s), annealing at $58{ }^{\circ} \mathrm{C}$ for AmSesTPS1 and $60{ }^{\circ} \mathrm{C}$ for AmGuaiS1 (30 s), and extension at $72{ }^{\circ} \mathrm{C}(5 \mathrm{~s})$. For 3' RLM-RACE, all the reverse transcriptase steps were the same as $5^{\prime}$ RLM-RACE, except for the template where $1 \mu \mathrm{g}$ of total RNA was used. PCR was carried out as described in $5^{\prime}$ RLM-RACE using only outer primer (3' RACE Outer Primer). PCR products of expected size were purified, cloned and the putative plasmid DNAs were sent for sequencing as mentioned above. 
Table 1 Specific primers used in PCR analysis to obtain AmSesTPS1 and AmGuaiS1 CDNAs and the primers used in qRT-PCR

\begin{tabular}{|c|c|c|c|}
\hline Amplification/gene & Primer name & Sequence ( $5^{\prime}$ to $\left.3^{\prime}\right)$ & Amplicon size (bp) \\
\hline \multirow[t]{4}{*}{ Internal } & SesTPS1 F & 5'-GCACTTGATTTCACCACGAAGCAC-3' & 930 \\
\hline & SesTPS1 R & 5'-GCTTCCCACTTCGTTGCCCCGTA-3' & \\
\hline & GuaiS1 F & 5'-ACACCGCACCGCCGAAACG-3' & 1350 \\
\hline & GuaiS1 R & 5'-AGCCGCCGAGATGCCAATTACC-3 & \\
\hline \multirow[t]{4}{*}{ 5' RACE } & AmSesTPS1 out & 5'- CTCTCTCAGCTCGTTTTGGTGCAAC-3' & \\
\hline & AmSesTPS1 in & 5'-ACAGTACTTAGCATCCAGCCTTGGG-3' & \\
\hline & AmGuais1 out & 5'-GAAGCAGTTGAGAGGTGGGACATTG-3' & \\
\hline & AmGuais1 in & 5'-ATGTTGATTGGAAGGGCAGAGTTTG-3' & \\
\hline \multirow[t]{2}{*}{ 3' RACE } & AmSesTPS1 out & 5'-GAATCCACACCAGCAGTTGCCCT-3' & \\
\hline & AmGuaiS1 out & 5'-TCCCACGCCTAGACGAATGATTTTG-3' & \\
\hline \multirow[t]{4}{*}{ ORF } & AmSesTPS1 full $F$ & 5'-GCAGCAATCAGGTTATTCAAAGGTC-3' & 1659 \\
\hline & AmSesTPS1 full $\mathrm{R}$ & 5'-GATTAATCGAGAGGAAGCTGGTGAAC-3' & \\
\hline & AmGuais1 full $F$ & 5'-ATGTCTTCGGCAAAACTAGGTTCTGC-3' & 1644 \\
\hline & AmGuais1 full $\mathrm{R}$ & 5'-TCAGATTTCGATAGCATGACGCAAC-3' & \\
\hline \multirow[t]{2}{*}{ qRT-PCR/AmSesTPS $1^{\mathrm{a}}$} & SESQ-F & 5'-GCA ACG AAG CGG GAA GCT GTG AA-3' & 238 \\
\hline & SESQ-R & 5'-TACCCTAAACGAATGGAAATATAGCG-3' & \\
\hline \multirow[t]{2}{*}{ qRT-PCR/AmGuais1 $1^{\mathrm{a}}$} & GUAl-F & 5'-TCA GAA GAA GAG GCA TGC AAG AAG A-3' & 251 \\
\hline & GUAI-R & 5'-GCA AGC TTC TTG GTT CGG TCA GA-3' & \\
\hline \multirow[t]{2}{*}{ qRT-PCR/AmRPL $L^{b}$} & RPL-F & 5'-CCG GTC TाT TGG TAT CAG ACG C-3' & 251 \\
\hline & RPL-R & 5'-CCC GAT AAC CAG GAC GTT CAA G-3' & \\
\hline \multirow[t]{2}{*}{ qRT-PCR/AmTUA } & TUA-F & 5'-GCC AAG TGA CAC AAG CGT AGG T-3' & 183 \\
\hline & TUA-R & 5'-TCC TTG CCA GAA ATA AGT TGC TC-3' & \\
\hline
\end{tabular}

aPrimer sequences were designed in this study

bPrimer sequences derived from Gao et al. (2012)

\section{Full-length cDNA sequence analysis}

To obtain the full-length sequence, overlapping regions were identified from the RACE amplifications and checked against the transcriptome sequence for verification. The full-length cDNA sequences analysis and interpretation were carried out using the Bioedit software (Version 5.0.6) for determination of molecular weight and prediction of acid nucleus content. Then, the sequences were analysed using the BLASTX program at the National Center of Biotechnology Information (NCBI) websites http://www.ncbi.nlm.nih.gov to search for homologs. ORFs were translated into amino acid sequences using the ORFinder at the NCBI website. CLUSTALW multiple alignment programs (http://www.ddbj.nig.ac.jp and http://mobyle.pasteur.fr) were used to align the amino acid sequences.

\section{Quantitative real-time reverse-transcription PCR}

For qPCR, a total of $1 \mu \mathrm{g}$ of total RNA was reverse transcribed into first-strand cDNA using the Quantitect Reverse Transcription (Qiagen, USA) kit following the manufacturer's instructions. Quantitative realtime reverse-transcription PCR (qRT-PCR) was performed using the SensiFAST ${ }^{\mathrm{mm}}$ SYBR Low-Rox Kit (Bioline, UK) according to the supplier's protocol. A $20 \mu \mathrm{L}$ reaction was prepared as follows: $10 \mu \mathrm{L}$ of $2 \times$ SensiFAST SYBR Low-ROX Mix, $1 \mu \mathrm{L}$ of cDNA template and $0.8 \mu \mathrm{L}$ each of $10 \mu \mathrm{M}$ forward and reverse primers and $7.4 \mu \mathrm{L}$ of distilled water. Amplification was conducted in the MX3005P $^{\text {тм }}$ QPCR Systems (Agilent Technologies, USA), and the program consisted of an initial denaturation at $94{ }^{\circ} \mathrm{C}$ ( $2 \mathrm{~min}$ ) followed by 40 cycles of denaturation at $94{ }^{\circ} \mathrm{C}(5 \mathrm{~s})$, annealing at $60{ }^{\circ} \mathrm{C}(10 \mathrm{~s})$ and extension at $72{ }^{\circ} \mathrm{C}(5 \mathrm{~s})$. qRTPCR primers were designed using the Beacon Designer 7 (Biosoft, USA) software (Table 1).

For the standard curve, templates with known concentrations were prepared in serial dilutions. Next, the standard curve was generated by plotting the log of the initial template copy number against the $C_{\mathrm{t}}$ generated for each dilution. $C_{\mathrm{t}}$ is the intersection between an amplification curve and a threshold line. It is a relative measure of the concentration of target in the PCR reaction. Fluorescence analyses (amplification, melting and standard curves) were carried out automatically by the realtime thermal cycler upon completion of the cycles. Each $C_{\mathrm{t}}$ value was obtained by means of three replicates. 


\section{Analysis of qRT-PCR data}

For expression analysis of AmSesTPS1 and AmGuaiS1 gene, the SESQ-F, SESQ-R and GUAI-F, GUAI-R primers were utilised. Primers were designed using the Beacon Designer 7 software (Premier Biosoft, USA). Two housekeeping genes encoding for the ribosomal protein (RPL) and tubulin (TUA) were used as reference genes (Gao et al. 2012). All primer sequences are listed in Table 1 . The $C_{\mathrm{t}}$ values were transformed to quantities using the comparative $C_{\mathrm{t}}$ method. For normalisation, two reference genes were used and normalisation factor was calculated by geNorm software (Vandesompele et al. 2002). The normalised expression level of gene of interest (GOI) was calculated by dividing the raw GOI quantities with the appropriate normalisation factor. Next, the standard deviation (SD) and standard error on the normalised gene of interest $\left(\mathrm{GOI}_{\text {norm }}\right)$ expression levels were calculated by applying the error propagation rules for independent variables.

\section{Results}

\section{Isolation of full-length cDNA}

We successfully isolated two genes in the terpene synthesis pathway from in vitro plantlets of $A$. malaccensis using reverse transcriptase PCR and specific primers. Initially, TPS-encoding genes of partial lengths were amplified using primers derived from sequences of $A$. malaccensis transcriptome (Siah et al. 2016) that matched with high homology to the corresponding candidate genes. PCR products of 932 and 1352 bp for AmSesTPS1 and AmGuaiS1, respectively, were obtained and their identities determined by BLASTX searches against the GenBank database. The AmSesTPS1 fragment shared $87 \%$ identity to sesquiterpene synthase and $85 \%$ identity to putative (-) germacrene-D synthase (SesTPS), both from Aquilaria sinensis (Lour.) Spreng., while the amplified portion of AmGuaiS1 shared $98 \%$ identity to $\delta$-guaiene synthase genes from Aquilaria crassna Pierre ex Lecomte (clone 2) and A. sinensis (ASS3).

The full-length cDNA sequence of AmSesTPS1 was amplified using the 5' RACE and 3' RACE primers from callus tissue of $A$. malaccensis. For AmGuaiS1, the size of the PCR product for 5' RACE and 3' RACE were $700 \mathrm{bp}$. Sequences were analysed by identifying overlapping regions between the partial fragments and the $5^{\prime}$ and 3' RACE products. In this way, the full-length AmSesTPS1 cDNA sequence of 1942 bp was obtained. The AmSesTPS1 cDNA contains an open-reading frame (ORF) of 1632 bp flanked by a 76 bp $5^{\prime}$ untranslated region (UTR) and 234 bp of 3' UTR. The start codon appeared at position $77 \mathrm{bp}$ and the stop codon at $1629 \mathrm{bp}$. A putative polyadenylation signal was predicted at $57 \mathrm{bp}$ upstream of the poly (A) tail at position $1815 \mathrm{bp}$. The predicted $\mathrm{G}+\mathrm{C}$ content is $44.49 \%$, and the $\mathrm{A}+\mathrm{T}$ content is $55.51 \%$. The predicted AmSesTPS1 encoded a sesquiterpene synthase protein of 543 amino acids with molecular weight of $62.688 \mathrm{kD}$.

Meanwhile, the AmGuaiS1 cDNA contains an ORF of 1644 bp flanked by a 71 bp 5' UTR and $162 \mathrm{bp}$ of 3 ' UTR. The start codon was at position $72 \mathrm{bp}$ and the stop codon at $1641 \mathrm{bp}$. The putative polyadenylation signal was predicted at $57 \mathrm{bp}$ upstream of the poly (A) tail at position $1711 \mathrm{bp}$. The predicted $\mathrm{G}+\mathrm{C}$ content is $42.52 \%$, and the $\mathrm{A}+\mathrm{T}$ content is $57.48 \%$. The predicted AmGuaiS1 encoded a $\delta$-guaiene synthase protein of 547 amino acids with molecular weight of $63.94 \mathrm{kD}$. Both sequences had been deposited into the GenBank with the accession numbers KT380853 and KT380854 for AmSesTPS1 and AmGuaiS1, respectively.

The full-length cDNAs were transcribed into amino acid sequences and then searched using BLASTX to the GenBank for identification of homologs. BLASTX analysis showed a high similarity in amino acid identity between AmSesTPS1 and other sesquiterpene synthases from known plant species. It shared $85 \%$ similarity with putative (-) germacrene-D synthase (As1) and sesquiterpene synthase (As2) from A. sinensis, followed by lower similarities $(50 \%)$ with (-) germacrene-D synthase from Morus notabilis C.K. Schneid. and a putative $\delta$-cadinene synthase isozyme A from Theobroma cacao L. Multiple alignments of deduced amino acid sequences of the cloned AmSesTPS1 and known sesquiterpene synthase genes were performed using CLUSTALW with BOXSHADE (http://mobyle.pasteur.fr.) (Fig. 2). From the alignment, there are many conserved residues observed among these five species and also a few in identical and similar residues. Conserved residues refer to the different individuals sharing the same amino acid in a sequence when aligned, while identical and similar residues refer to the different individuals having a different amino acid in a sequence when aligned yet the amino acid mutation is within the same amino acid class. A comparison between the deduced amino acid sequences of AmGuaiS1 with other $\delta$-guaiene synthases showed that it shared $99 \%$ similarity with $\delta$-guaiene synthases isolated from Aquilaria microcarpa, A. crassna and A. sinensis, all are close relatives of A. malaccensis. Multiple alignments of deduced amino acid sequences of the cloned AmGuaiS1 and known $\delta$-guaiene synthases revealed several stretches of long conserved domain regions (Fig. 3).

\section{Gene expression analysis}

For gene expression, a total of 24 trees were drillwounded and sampled at different time points: 2, 4, 6, 8, 12, 18, 24 and $48 \mathrm{~h}$. Three unwounded trees were 


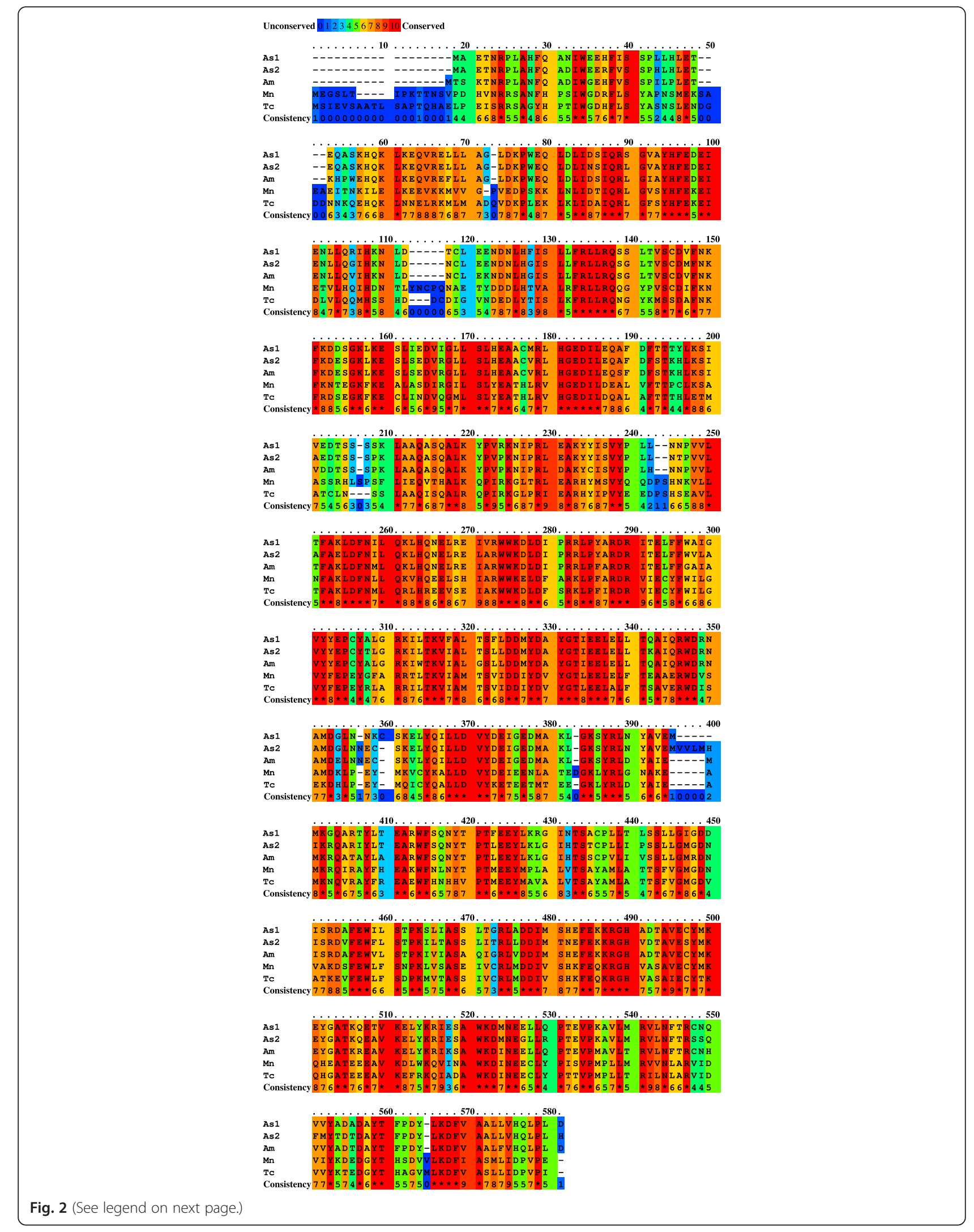


(See figure on previous page.)

Fig. 2 Multiple sequence alignments of sesquiterpene synthases from various plant species. Amino acid sequences from Aquilaria malaccensis (Am) was aligned with those from Aquilaria sinensis (As1, GenBank accession no. AGV40227.1, and As2, GenBank accession no. AGV 40228.1), Morus notabilis (Mn, GenBank accession no. EXB50826.1) and Theobroma cacao (Tc, GenBank accession no. XP 00701115.1). Alignment of the amino acid sequences was obtained using CLUSTALW with BOXSHADE (http://bioweb.pasteur.fr), in which gaps are marked as dashes and the conserved residues are highlighted in red, identical residues in yellow to orange and similar residues in green

sampled as controls to represent $0 \mathrm{~h}$. For each time point, there were three biological replicates and two sampling points, S1 and S2. This gave a total of 54 samples. Total RNAs were successfully extracted from every wood sample; sharp $18 \mathrm{~S}$ and $25 \mathrm{~S}$ bands were observed for the samples (Fig. 4), indicating they were of acceptable quality for qRT-PCR.

Normalised expressions of the AmSesTPS1 and AmGuaiS1 genes to the housekeeping genes were quantified in the 54 samples using the same batch of cDNAs to minimise experimental variation. The expression patterns of AmSesTPS1 and AmGuaiS1 throughout the time course after drill wounding were monitored and compared between S1 and S2 samples, both were from wounded trees, while unwounded tree served as the control. For AmSesTPS1, both sample types showed similar patterns in expression after wounding (Fig. 5a). The expression increased rapidly from 0 to $4 \mathrm{~h}$ and reached its highest level at $6 \mathrm{~h}$, sixfold and threefold that of control, in S1 and S2, respectively. However, the expression level drastically decreased to about the same level of control until it increased again at $48 \mathrm{~h}$ (2.5-fold); this was only true for S1. In S2, the level at $48 \mathrm{~h}$ stayed low. For AmGuaiS1, similar pattern in expression as AmSesTPS1 was observed. However, the level peaked earlier at $2 \mathrm{~h}$, about 18-fold when compared to the control at S1 and 5.5 -fold at S2 (Fig. 5b), after which it dropped. At $24 \mathrm{~h}$, the expression level re-increased to 16-fold and 4.4-fold at S1 and S2, respectively, but was lowered again at $48 \mathrm{~h}$. The high expression of AmGuaiS1 in the wood sample, $2 \mathrm{~h}$ after wounding might be related to early increased transcript level of AmGuais1, similar to the wound-induced transcript of linalool synthase (PSTPSLinl) and limonene synthase (PSTPS-Lim) in Picea sitchensis (Bong.) Carr (Sitka spruce) (McKay et al. 2006).

The average expression throughout all time points was quantified for S1 and S2 and compared to unwounded $(0 \mathrm{~h})$ control (Fig. 6). Means of expression for both genes in samples S1 and S2 showed an induced expression, suggesting that the genes were not exclusively expressed in the wounded area (Fig. 6). Therefore, it is reasonable to suppose that a process of signal transduction mediated by the act of wounding had happened in both areas, before the strong expression of the sesquiterpene synthase genes became evident at the early period of agarwood formation.

\section{Discussion}

We isolated full-length cDNA sequences of sesquiterpene synthase genes, an important enzyme in the terpene synthase pathway that controls the production of sesquiterpene compounds, which are abundant in agarwood. The AmSesTPS1 is highly similar to the genes that encode for germacrene-D synthases identified in a few plant species such as in Actinidia deliciosa (A.Chev.) C.F.Liang \& A.R.Ferguson, Vitis vinifera L. and Zingiber officinale Roscoe (Lücker et al. 2004; Picaud et al. 2006). Germacrene-D is a sesquiterpene produced from farnasyl diphosphate catalysed by the enzyme germacrene-D synthase (Picaud et al. 2006). This volatile compound has ecological function, and it is involved in the interaction between plant and insect enemy (Røstelien et al. 2000). In several plants, germacrene-D synthase was found to be induced by insects (Arimura et al. 2004). Expression of TPS genes is positively regulated by mechanical wounding (McKay et al. 2006), insect attack (Miller et al. 2005) and methyl jasmonate (Fäldt et al. 2003).

A previous study showed that the production of three species of sesquiterpenes ( $\alpha$-guaiene, $\alpha$-humulene and $\delta$ guaiene) was possible by exposure to methyl jasmonate (MJ), which acts as an elicitor of plant defense response in cultured cells of Aquilaria crassna (Ito et al. 2005; Okudera and Ito 2009). Guaiene-type sesquiterpenes are synthesised through two cyclisation reactions, the first composed of a $\mathrm{C} 1$ to $\mathrm{C} 10$ cyclisation, yielding an intermediate macrocyclic germacrene, while the second reaction, $\mathrm{C} 2$ to $\mathrm{C} 6$ yielding the guaiene products. In nature, guaiene-type sesquiterpenes are unique, being composed of five to seven membered rings, and a few enzymes are involved in its production (Steele et al. 1998; Deguerry et al. 2006). Due to the high similarity of AmGuaiS1 with guaiene synthases from other Aquilaria species such as $A$. crassna, it can be deduced that the gene possibly plays a role in guaiene synthesis in A. malaccensis.

Members of the terpene synthase group are mostly sesquiterpene synthases with many having roles in ecological plant interaction, compared to roles in primary plant metabolism (Chen et al. 2011). In Aquilaria, the sesquiterpene-rich agarwood is formed in the wood primarily when the tree is wounded (Pojanagaroon and Kaewrak 2005). Indeed, treatments such as mechanical wounding, fungal infection, artificial introduction of some chemicals and others have been shown to trigger 

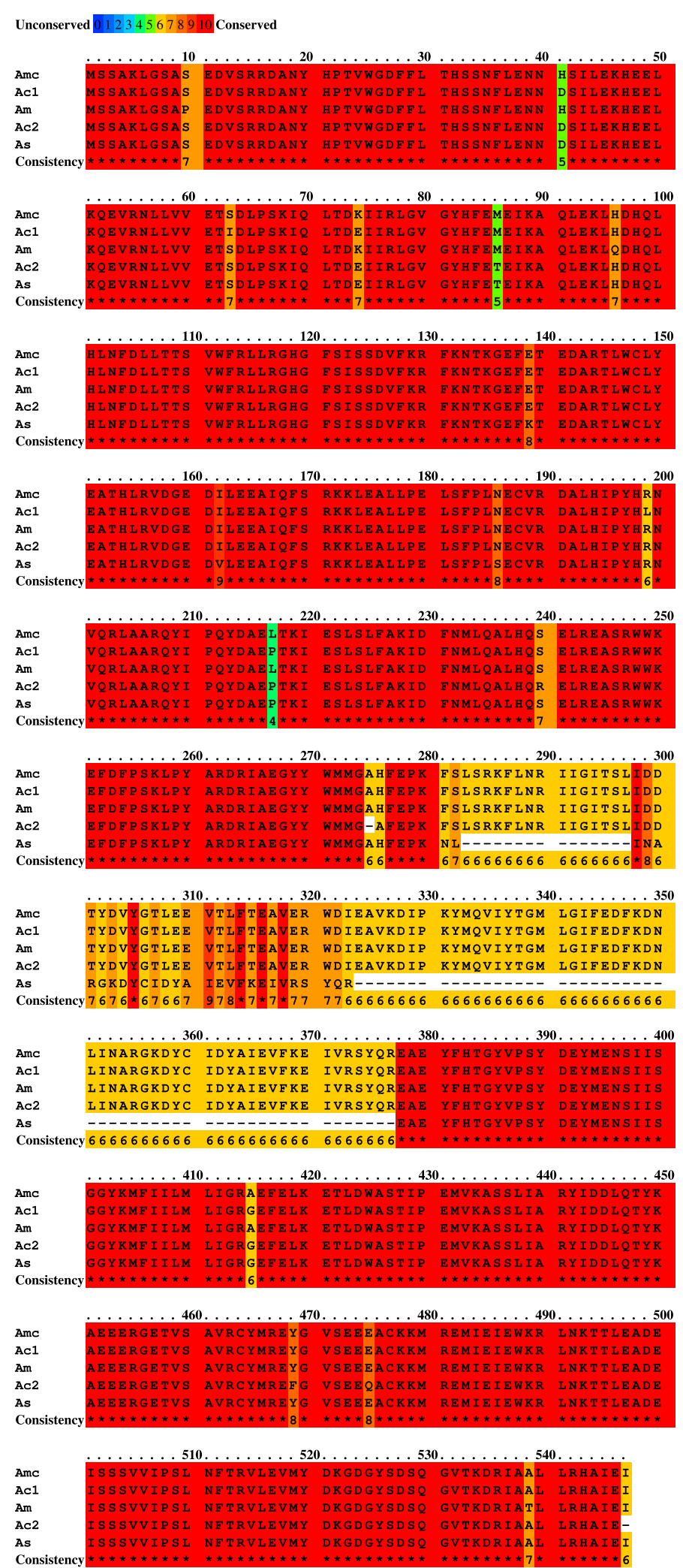

Fig. 3 (See legend on next page.) 
(See figure on previous page.)

Fig. 3 Multiple sequence alignments of $\delta$-guaiene synthases from different Aquilaria species. Amino acid sequences from Aquilaria malaccensis (AmGuaiS1) were aligned with those from Aquilaria crassna (Ac1, GenBank accession no: AEG77018.1, and Ac2, GenBank accession no. AEG77019.1), Aquilaria microcarpa (Amc, GenBank accession no. AHH25146.1) and Aquilaria sinensis (As, GenBank accession no. AFV99466.1). Alignment of the amino acid sequences was obtained using CLUSTALW with BOXSHADE (http://bioweb.pasteur.fr), in which gaps are marked as dashes and the conserved residues are highlighted in red, identical residues in yellow to orange and similar residues in green

agarwood formation in Aquilaria spp. (Tabata et al. 2002; Mohamed et al. 2014a). Gene expression analysis revealed that AmSesTPS1 and AmGuaiS1 were both responsive to mechanical wounding and thus can be associated to formation of agarwood sesquiterpenes. The highest level was at 6 and $2 \mathrm{~h}$ for AmSesTPS1 and AmGuaiS1, respectively, after which it dropped and re-elevated at 48 and $24 \mathrm{~h}$, respectively. Both were highly expressed in the hours shortly after wounding, suggesting a substantial response to wounding. The expression level decreased in the following hours but re-increased again a day or two later, indicating inductions by secondary factors such as fungi, could be possible, as the experiment was conducted in open surroundings. High levels of fungi have been detected during the first few hours and days after artificial

\section{UC 2h 4h 6h 8h 12h 18h 24h 48h}

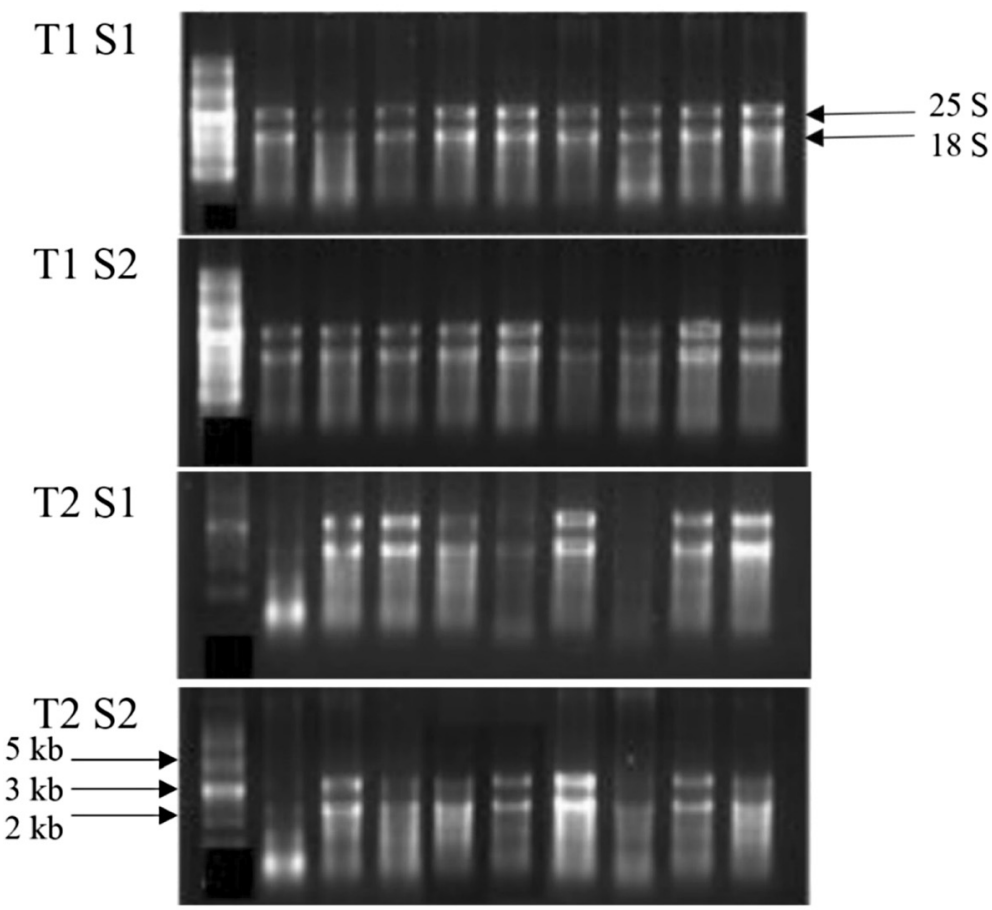

T3 S1

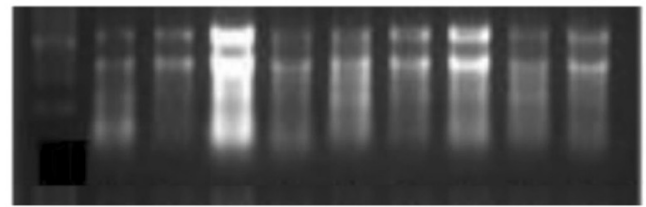

T3 S2

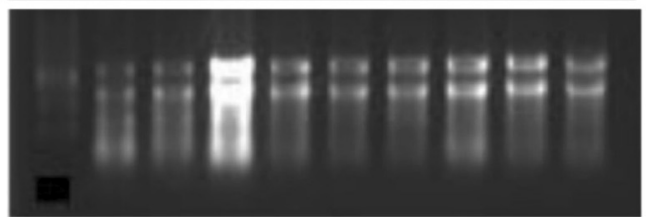

Fig. 4 Gel electrophoresis of total RNAs from wounded and unwounded Aquilaria malaccensis. Samples were wood tissues collected from a total of 27 trees. A set of three trees (T1-T3) were harvested at each time point and two types of samples (S1 and S2) were withdrawn from each tree stem at 2 to $48 \mathrm{~h}$ post wounding and the unwounded controls (UC). $M$ is a single-stranded RNA ladder 


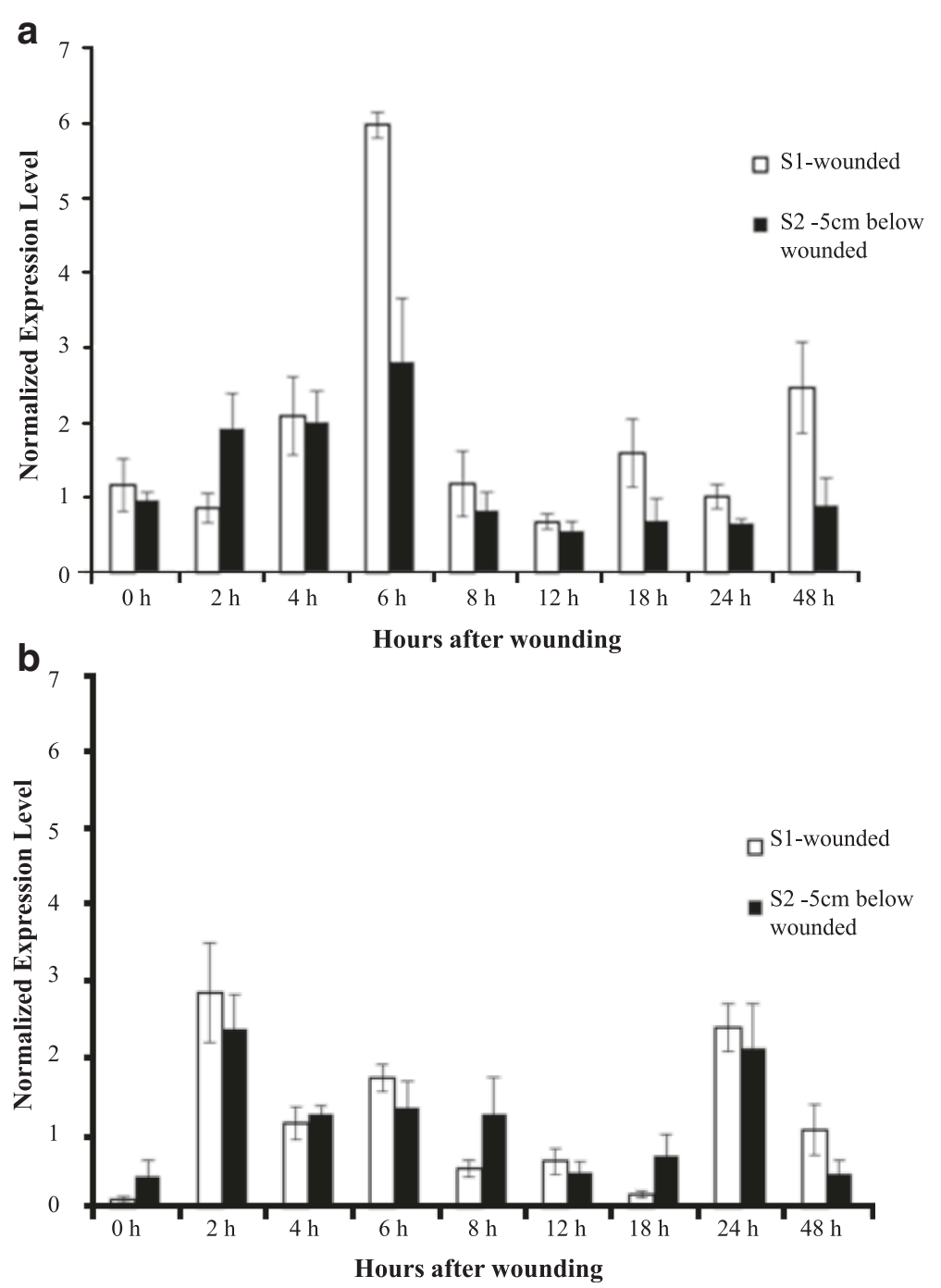

Fig. 5 qRT-PCR expression levels of a AmSesTPS1 and $\mathbf{b}$ AmGuaiS1 in wounded stem of Aquilaria malaccensis at different time points. RPL and TUA genes were used as internal controls for normalisation. Bars represent level of expression as analysed from three technical replicates and the error bars represent standard errors. White bars represent samples collected from wounded area (S1) while black bars represent samples collected $5 \mathrm{~cm}$ below the wounded area (\$2)

wounding but were reduced many months later in wild Aquilaria trees (Mohamed et al. 2014b). Fungi normally take time to infect and then to colonise the wood tissues. These results showed the importance of both genes in responding to both abiotic and biotic attacks in $A$. malaccensis. This is similar to expression of monoterpene synthase (mono-tps) in Sitka spruce, which had increased expression within 24-48 h in combined xylem and bark tissues upon weevil attack (McKay et al. 2006).

The wood colour of $A$. malaccensis had changed from white to brown around the drilled area, which indicates induction of secondary metabolism. This is consistent with observations made related to wound effects on A. malaccensis trees at different time point after drilling (Mohamed et al. 2014b). When comparing the expression of both genes in the two sample types, S1 and S2, an enhanced expression was observed. This suggests that cells in direct contact with inducing factor such as those that are present in the wounded area are unlikely to express the TPS genes at a higher magnitude, compared to those that are far away from the point of wounding. However, responses to environmental stimuli can happen in seconds; therefore, expression levels of the genes at earlier points $(<2 \mathrm{~h})$ could be different if their onset were at a very early stage after wounding. The degree of gene expression was not affected by the increasing distance from the wounding site perhaps due to the existence of signal molecules, such as $\mathrm{H}_{2} \mathrm{O}_{2}$, nitric oxide, jasmonic acid 


\section{a AmSesTPS1}

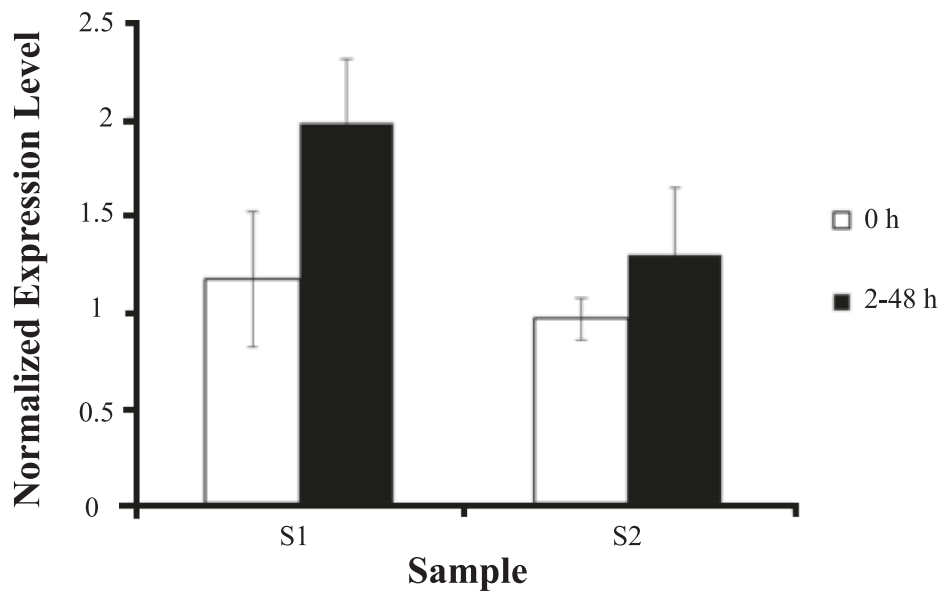

\section{b AmGuail}

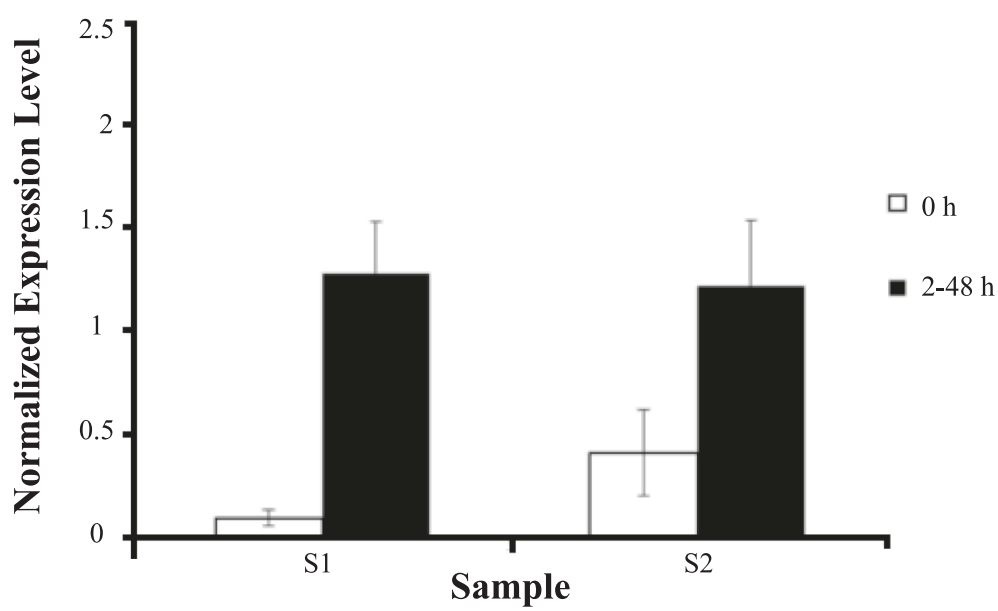

Fig. 6 Mean qRT-PCR expression levels of a AmSesTPS1 and $\mathbf{b}$ AmGuaiS1, in wounded Aquilaria malaccensis from all time points (2-48 h) at the two sample locations compared to the unwounded control. White bars represent samples collected from wounded area (S1) while black bars represent samples collected $5 \mathrm{~cm}$ below the wounded area (S2). Error bars indicate standard errors of the means from all wounding time points

and ethylene, which play known functions in the cross-talk events among organelles and cells under physiological and stress conditions (Zhao et al. 2005; Vasconsuelo and Boland 2007; Hou et al. 2013). Agarwood formation at the early phase indeed involves wound signalling transduction process through the activation of several transcription factors, such as MYB4, MYC, WRKY4, EIN3, ERF and bZip, which are commonly involved in stress responses (Xu et al. 2003). Agarwood sesquiterpene is a typical inducible secondary metabolite; mechanical wounding and chemical treatment are known to induce sesquiterpene substance production. However, besides the type of inducers, the method of applying the inducer highly affects the effectiveness and yield of agarwood. Wounding appears to yield agarwood that is confined to the wounding site (Wong et al. 2013). Although TPS genes were triggered quite a distance from the wounding site, agarwood production was not observed. Liu et al. 2013 reported an application that yields a systemic reaction, where agarwood is induced in the whole tree by applying chemical inducers from several points of introduction along the stem. This method seems to be more attractive, requires less handling and reduces biomass waste. From these two application methods, it can be suggested that agarwood production can be triggered through different transduction pathways in local and systemic reactions. There are also numerous mobile molecules in xylem and phloem conduits such as peptides and RNA molecules that could help in longdistance signalling pathway; however, their roles in plant development and physiology are still largely unknown (Notaguchi and Okamoto 2015). 


\section{Conclusions}

In conclusion, two new genes from the terpenoid synthesis pathway, designated as AmSesTPS1 and AmGuaiS1 were successfully cloned from $A$. malaccensis. Quantitative expression analysis suggests both are wound inducible genes that respond early after wounding and could be reinduced later if given secondary triggers such as naturally occurring biological infestation. Agarwood is rich in secondary metabolites, specifically sesquiterpenes. Therefore, the identification of TPS genes provides new information for molecular investigation of TPSs in general and possibly contributes to another perspective on the diversity and evolutionary of TPSs found in nature. These findings provide new genes that may be used for generating specific compounds of interest from agarwood via in vitro methods such as through metabolic engineering.

\section{Acknowledgements}

This project was supported by the Universiti Putra Malaysia, Research University Grant Scheme (Project No. 03-03-11-1438RU).

\section{Authors' contributions}

All authors have contributed substantially to this manuscript and were involved in planning, data analyses and manuscript writing. ABA and SYL carried out sample treatments; ABA carried out the experiments, analysis and drafted the manuscript; RM conceived the idea of the study, participated in its design and analysis, drafted and reviewed the manuscript. MN reviewed the manuscript. All authors read and approved the final manuscript.

\section{Competing interests}

The authors declare that they have no competing interests.

\section{Author details}

${ }^{1}$ Forest Biotech Laboratory, Department of Forest Management, Faculty of Forestry, Universiti Putra Malaysia, 43400 UPM Serdang, Selangor, Malaysia. ${ }^{2}$ Department of Forest Management, Faculty of Forestry, Universiti Putra Malaysia, 43400 UPM Serdang, Selangor, Malaysia.

Received: 24 November 2015 Accepted: 29 May 2016 Published online: 20 June 2016

\section{References}

Arimura, G. I., Huber, D. P. W., \& Bohlmann, J. (2004). Forest tent caterpillars (Malacosoma disstria) induce local and systemic diurnal emissions of terpenoid volatiles in hybrid poplar (Populus trichocarpa $x$ deltoides): cDNA cloning, functional characterisation, and patterns of gene expression of (-)-germacrene D synthase, PtdTPS1. Plant Journal, 37, 603-616.

Bates, R. B., \& Slagel, R. C. (1962). Terpenoids. VI. $\beta$-Bulnesene, a-guaiene, $\beta$-patchoulene, and guaioxide in essential oils. Chemistry \& Industry, 1, 1715-1716.

Chen, F., Tholl, D., Bohlmann, J., \& Pichersky, E. (2011). The family of terpene synthases in plants: a mid-size family of genes for specialised metabolism that is highly diversified throughout the kingdom. Plant Journal, 66(1), 212-229.

Daud, N. H., Jayaraman, S., \& Mohamed, R. (2012). An improved surface sterilization technique for introducing leaf, nodal and seed explants of Aquilaria malaccensis from field sources into tissue culture. Asia-Pacific Journal of Molecular Biology and Biotechnology, 20(2), 55-58.

Deguerry, F., Pastore, L., Wu, S., Clark, A., Chapell, J., \& Schalk, M. (2006). The diverse sesquiterpene profile of patchouli, Pogostemon cablin, is correlated with a limited number of sesquiterpene synthases. Archives Biochemistry Biophysics, 454(2), 123-136.

Fäldt, J., Martin, D., Miller, B., Rawat, S., \& Bohlmann, J. (2003). Traumatic resin defense in Norway spruce (Picea abies): Methyl jasmonate-induced terpene synthase gene expression, and cDNA cloning and functional characterization of (+)-3-carene synthase. Plant Molecular Biology, 51, 119-133.
Gao, Z. H., Wei, J. H., Yang, Y., Zhang, Z., \& Zhao, W. T. (2012). Selection and validation of reference genes for studying stress-related agarwood formation of Aquilaria sinensis. Plant Cell Reports, 31(9), 1759-1768.

He, M. L., Qi, S. Y., \& Hu, L. J. (2005). Rapid in vitro propagation of medicinally important Aquilaria agallocha. Journal of Zhenjiang University Science B, 6(8), 849-852

Hou, S., Zhang, C., Yang, Y., \& Wu, D. (2013). Recent advances in plant immunity: recognition, signaling, response, and evolution. Biologia Plantarum, 57(1), 11-25.

Ito, M., Okimoto, K., Yagura, T., Honda, G., Kiuchi, F., \& Shimada, Y. (2005). Induction of sesquiterpenoid production by methyl jasmonate in Aquilaria sinensis cell suspension culture. Journal of Essential Oil Research, 17(2), 175-180.

Jayaraman, S., \& Mohamed, R. (2015). Fungal extract elicits agarwood substances in cell suspension culture of Aquilaria malaccensis Lam. Turkish Journal of Agriculture and Forestry, 39, 163-173.

Liu, Y. Y., Chen, H. Q., Yang, Y., Zhang, Z., Wei, J. H., Meng, H., Chen, W. P, Feng, J. D., Gan, B. C., Chen, X. Y., Gao, Z. H., Huang, J. Q., Chen, B., \& Chen, H. J. (2013). Whole-tree agarwood-inducing technique: an efficient novel technique for producing high-quality agarwood in cultivated Aquilaria sinensis trees. Molecules, 18(3), 3086-3106.

Lücker, J., Bowen, P., \& Bohlmann, J. (2004). Vitis vinifera terpenoid cyclases: functional identification of two sesquiterpene synthase cDNAs encoding (+)- valencene synthase and (-)-germacrene D synthase and expression of mono- and sesquiterpene synthases in grapevine flowers and berries. Phytochemistry, 65(19), 2649-2659.

McKay, S. A., Hunter, W. L., Godard, K. A., Wang, S. X., Martin, D. M., Bohlmann, J., \& Plant, A. L. (2006). Insect attack and wounding induce traumatic resin duct development and gene expression of (-)-pinene synthase in Sitka spruce. Plant Physiology, 133, 368-378.

Miller, B., Madilao, L. L., Ralph, S., \& Bohlmann, J. (2005). Insect-induced conifer defense: White pine weevil and methyl jasmonate induce traumatic resinosis, de novo formed volatile emissions and accumulation of terpenoid synthase and putative octadecanoid pathway transcripts in Sitka spruce. Plant Physiology, 137(1), 369-382.

Mohamed, R., Jong, P. L., \& Kamziah, A. K. (2014a). Fungi inoculation induced agarwood in young Aquilaria malaccensis trees in the nursery. Journal of Forestry Research, 25(1), 201-204.

Mohamed, R., Jong, P. L., \& Nurul Irdayu, I. (2014b). Succession patterns of fungi associated to wound-induced agarwood in wild Aquilaria malaccensis revealed from quantitative PCR assay. World Journal of Microbiology and Biotechnology, 30(9), 2427-2436.

Mohamed, R., Jong, P. L., \& Zali, M. S. (2010). Fungal diversity in wounded stems of Aquilaria malaccensis. Fungal Diversity, 43, 67-74.

Murashige, T., \& Skoog, F. (1962). A revised medium for rapid growth and bioassays with tobacco tissue culture. Physiology Plant, 15, 473-497.

Naef, R. (2011). The volatile and semi-volatile constituents of agarwood, the infected heartwood of Aquilaria species: a review. Flavour Fragrance Journal, $26,73-87$.

Nobuchi, T., \& Mohd Hamami, S. (2008). The formation of wood in tropical trees: a challenge from the perspective of functional wood anatomy. Serdang: Penerbit Universiti Putra Malaysia.

Notaguchi, M., \& Okamoto, S. (2015). Dynamics of long-distance signaling via plant vascular tissues. Frontiers in Plant Science, 6, 161

Okudera, Y., \& Ito, M. (2009). Production of agarwood fragrant constituents in Aquilaria calli and cell suspension cultures. Plant Biotechnology, 26, 207-315.

Okugawa, H., Ueda, R., Matsumoto, K., Kawanishi, K., \& Kato, K. (2000). Effects of sesquiterpenoids from "Oriental incenses" on acetic acid-induced writhing and D2 and 5-HT2A receptors in rat brain. Phytomedicine, 7(5), 417-22.

Picaud, S., Olsson, M. E., Brodelius, M., \& Brodelius, P. E. (2006). Cloning, expression, purification and characterization of recombinant (+)-germacrene D synthase from Zingiber officinale. Archives of Biochemistry and Biophysics, 452(1), 17-28.

Pojanagaroon, S., \& Kaewrak, C. (2005). Mechanical methods to stimulate aloes wood formation in Aquilaria crassna Pierre ex H. Lec. (Kritsana) trees. ISHS Acta Horticuturae, 676, 161-166.

Rasool, S., \& Mohamed, R. (2015). Plant cytochrome P450s: nomenclature and involvement in natural product biosynthesis. Protoplasma. doi:10.1007/ s00709-015-0884-4

Røstelien, T., Borg-Karlson, A. K., Fäldt, J., Jacobsson, U., \& Mustaparta, H. (2000). The plant sesquiterpene germacrene-D specifically activates a major type of antennal receptor neuron of the tobacco budworm moth Heliothis virescens. Chemical Senses, 25(2), 141-148. 
Siah, C. H., Namasivayam, P., \& Mohamed, R. (2012). Comparison of different RNA extraction methods on woody tissues of the tropical tree, Aquilaria malaccensis. Asia-Pacific Journal of Molecular Biology and Biotechnology, 20(3), 107-113.

Siah, C. H., Namasivayam, P., \& Mohamed, R. (2016). Transcriptome reveals senescing callus tissue of Aquilaria malaccensis, an endangered tropical tree, triggers similar response as wounding with respect to terpenoid biosynthesis. Tree Genetics \& Genomes, 12, 33-42.

Steele, C. L., Crock, J., Bohlmann, J., \& Croteau, R. (1998). Sesquiterpene synthases from grand fir (Abies grandis). Comparison of constitutive and woundinduced activities and cDNA isolation, characterization and bacterial expression of delta-selinene synthase and gamma-humulene synthase. Journal of Biological Chemistry, 273, 2078-2089.

Tabata, Y., Widjaja, E., Mulyaningsih, T., Parman, I., Wiriadinata, H., Mandang, Y. I., \& Itoh, T. (2002). Structure survey and artificial induction of aloeswood. Wood Research, 90, 11-12.

Ueda, J. Y., Imamura, L., Tezuka, Y., Tran, Q. L., Tsuda, M., \& Kadota, S. (2006). New sesquiterpene from Vietnamese agarwood and its induction effect on brainderived neurotrophic factor mRNA expression in vitro. Bioorganic \& Medicinal Chemistry, 14(10), 3571-3574.

Vandesompele, J., Preter, K. D., Pattyn, F., Poppe, B., Roy, N. V., Paepe, A. D., \& Speleman, F. (2002). Accurate normalization of real-time quantitative RT-PCR data by geometric averaging of multiple internal control genes. Genome Biology, 3(7), 0034

Vasconsuelo, A., \& Boland, R. (2007). Molecular aspects of the early stages of elicitation of secondary metabolites in plants. Plant Science, 172(5), 861-875.

Wong, M. T., Siah, C. H., Faridah, Q. Z., \& Mohamed, R. (2013). Characterization of wound-responsive genes in Aquilaria malaccensis. Journal of Plant Biochemistry and Biotechnology, 22, 168-175.

Xu, Y. H., Zhang, Z., Wang, M. X., Wei, J. H., Chen, H. J., Gao, Z. H., Sui, C., Luo, H. M., Zhang, X. L., Yang, Y., Meng, H., \& Li, W. L. (2003). Identification of genes related to agarwood formation: transcriptome analysis of healthy and wounded tissues of Aquilaria sinensis. BMC Genomics, 14, 227.

Yagura, T., Ito, M., Kiuchi, F., Honda, G., \& Shimada, Y. (2003). Four new 2-(2phenylethyl) chromone derivatives from withered wood of Aquilaria sinensis. Chemical and Pharmaceutical Bulletin, 51(5), 560-564.

Zhao, J., Davis, L. C., \& Verpoorte, R. (2005). Elicitor signal transduction leading to production of plant secondary metabolites. Biotechnology Advances, 23(4), 283-333.

\section{Submit your manuscript to a SpringerOpen ${ }^{\odot}$ journal and benefit from:}

- Convenient online submission

- Rigorous peer review

- Immediate publication on acceptance

- Open access: articles freely available online

- High visibility within the field

- Retaining the copyright to your article

Submit your next manuscript at $>$ springeropen.com 